\title{
Analisis Faktor-Faktor yang Mempengaruhi Ketahanan Hidup Pasien Tuberculosis dengan Model Regresi Cox (Studi kasus : Rumah Sakit Paru Bogor)
}

\author{
Ani Andriyati ${ }^{1, \text { a) }}$ dan Embay Rohaeti ${ }^{2, \text { b) }}$ \\ ${ }^{1}$ Program Studi Matematika Universitas Pakuan \\ ${ }^{2}$ Program Studi Matematika Universitas Pakuan \\ a)email:ani.andriyati2@gmail.com \\ b)email:embayrohaeti@gmail.com
}

\begin{abstract}
Abstrak
Ketahanan hidup penderita tuberculosis dipengaruhi oleh faktor eksternal maupun internal. Beberapa faktor yang dapat mempengaruhi ketahanan hidup seorang penderita tuberculosis diantaranya yaitu usia, jenis kelamin, tingkat pendidikan, sanitasi lingkungan, kebiasaan merokok dan pencahyaan rumah. Analisis survival dapat menganalisis ketahanan hidup seorang penderita penyakit. Dalam mengetahui faktor-faktor yang mempengaruhi ketahanan hidup penderita tuberculosis menggunakan analisis survival dengan model regresi cox. Adapun hasil dari analisis survival untuk ketahanan hidup pasien yaitu faktor sanitasi lingkungan, kebiasaan merokok dan mempunyai pencahayaan rumah mempengaruhi ketahanan hidup penderita tuberculosis. Data waktu survival berdistribusi 3-parameter weibull dengan parameter $\alpha, \beta$, dan $\lambda$ masing-masing bernilai $1.36794,8.48634$ dan -0.05489 . Hasil dari model regresi cox menunjukkan sanitasi lingkungan menjadi faktor yang paling mempengaruhi terhadap ketahanan hidup penderita tuberculosis Penderita dengan sanitasi lingkungan kurang baik akan meningkatkan fungsi hazard sebesar $\mathrm{e}^{1.237}$. Nilai Hazard ratio sanitasi sebesar $1 / 1.237$ atau 0.8084 menunjukkan bahwa risiko untuk sembuh penderita yang memiliki sanitasi kurang baik adalah 0.8084 kali dari penderita dengan sanitasi lingkungan yang baik.
\end{abstract}

Kata kunci: Tuberculosis, Regresi Cox, 3-Parameter Weibuyl, Analisis Survival, Ketahanan Hidup, Fungsi Hazard.

\begin{abstract}
Survival rate of tuberculosis patients can be affected by many factor such as age, sex, level of education, environment sanitation, smoking habit, and home lighting The factors were classified into two group: internal and external factor. We did survival analysis to tuberculosis patients to know the dominant factors affecting their survival rate. Using Cox regression model, we knew that environment sanitation, smoking habit, and home lighting are affecting their survival rate. We use Weibull distribution with 3 parameters namely $\alpha=1.36794, \beta=8.48634$, and $\lambda=-0.05489$. From the result, we also know that environment sanitation is the most dominant factor for the survival rate of tuberculosis patients. Hazard value of the patients having bad environment sanitation will increase $e^{1.237}$. Hence the hazard ratio of sanitation is equal to 0.8084 , and the risk of patient having bad sanitation is 0.8084 times the risk of patient having good sanitation.
\end{abstract}

Keywords: Tuberculosis, Cox regression, Survival analysis, Hazard function, Weibull 3-parameter. 


\section{Pendahuluan}

Tuberculosis (TB) merupakan penyakit infeksi yang masih menjadi masalah kesehatan diberbagai belahan dunia, termasuk Indonesia. TB merupakan salah satu penyakit menular yang jika tidak mendapatkan penanganan yang tepat bisa menimbulkan kejadian yang tidak diinginkan seperti halnya kematian. Menurut WHO (World Health Organization), pada tahun 1999 di Asia terdapat 4,5 juta kasus TB dari keseluruhan 8 juta [1]. Kasus TB yang diperkirakan terdapat di Indonesia sebanyak 3 juta yang mengalami kematian karena TB setiap tahunnya. Gejala yang ditimbulkan antara lain gangguan pernafasan seperti sesak nafas, batuk sampai berdarah, badan tampak kurus kering dan lemah.

Pemerintah Indonesia telah berupaya mengurangi jumlah penderita TB dengan memberikan penyuluhan terhadap warga di Indonesia. Pemerintah Indonesia pun bekerjasama dengan WHO melaksanakan evaluasi bersama yang menghasilkan rekomendasi perlunya melakukan perubahan mendasar pada strategi penanggulangan penyakit TB di Indonesia.

Ketahanan hidup penderita tuberculosis dipengaruhi oleh faktor eksternal maupun internal. Seseorang yang menderita TB, ketahanan hidupnya akan berkurang. Lama hidup penderita tersebut tergantung pada beberapa faktor. Faktor-faktor tersebut diantaranya faktor jenis kelamin dan usia [2], serta diduga tingkat pendidikan, sanitasi lingkungan, kebiasaan merokok, dan pencahayaan rumah juga menjadi faktor yang mempengaruhi ketahanan hidup penderita TB. Ketahanan hidup seorang penderita penyakit berhubungan dengan data survival sehingga analisis survival dapat digunakan[3]. Regresi cox merupakan pendekatan model matematika untuk menggambarkan kurva survival ketika mempertimbangkan beberapa faktor resiko secara bersamaan[4]. Analisis Survival dengan model regresi cox pernah dilakukan untuk menganalisis laju kesembuhan pasien Demam Berdarah Dengue di Rumah Sakit Haji Surabaya[5]. Dalam penelitian ini analisis survival dengan model regresi cox digunakan untuk mengetahui faktor-faktor yang mempengaruhi ketahanan hidup penderita tuberculosis di Rumah Sakit Paru Goenawan Partowidigdo (RSPG) Cisarua Bogor.

\section{Metode}

1. Identifikasi Variabel

Pada tahan 2 dilakukan identifikasi variabel-variabel yang akan dilibatkan dalam model. Terdapat dua jenis variabel yang akan digunakan, yaitu:

a. Variabel Dependen

Variabel dependen dalam penelitian ini yaitu waktu yang diperluan oleh penderita untuk bertahan hidup dari waktu awal (tanggal masuk penderita rawat inap di RSPG Cisarua) hingga waktu akhir (Tanggal akhir penelitian) yang dilambangkan dengan huruf " $T$ " dan satuan waktunya adalah hari. Publikasi Ilmiah Matematika

b. Variabel Independen

Variabel independen yang digunakan yaitu usia $\left(X_{1}\right)$, jenis kelamin $\left(X_{2}\right)$, tingkat pendidikan $\left(X_{3}\right)$, sanitasi lingkungan $\left(X_{4}\right)$, kebiasaan merokok $\left(X_{5}\right)$, dan pencahayaan rumah $\left(X_{6}\right)$.

2. Analisis Deskriptif

Untuk mengetahui karakteristik penderita penyakit tuberculosis yang dirawat di RS Paru Dr. Goenawan Partowidigdo, maka langkah analisis deskriptif yang dilakukan adalah :

a. Membuat bar chart setiap variabel independen untuk mengetahui karakteristik penderita.

$b$. Menganalisis karakteristik penderita berdasarkan nilai persentase pada pie chart.

c. Dilakukan pendugaan distribusi data menggunkan software Minitab, sehingga dapat diketahui jenis distrubusi data waktu survival penderita tuberculosis.

3. Estimasi fungsi hazard dan fungsi survival

Pada tahap ini dilakukan pendugaan fungsi hazard $\left(h(t)=\frac{f(t)}{1-F(t)}\right)$ dan fungsi survival $(S(t)=1-$ $F(t))$ dengan $F(t)$ merupakan fungsi kumulatif dari fungsi kepadatan peluang suatu distribusi yang akan dijadikan dasar dalam formulasi model. Pendugaan fungsi hazard dan fungsi survival dilakukan dengan mengikuti distribusi yang sudah diperoleh pada tahap sebelumnya. Pendugaan distribusi data menggunakan Anderson-Darling dan statistik ujinya adalah sebagai berikut [6]:

$A^{2}=-n-\frac{1}{n} \sum(2 i-1)\left[\ln F\left(X_{i}\right)+\ln \left(1-F\left(X_{n+1-i}\right)\right)\right]$ 
Data dapat dikatakan mengikuti distribusi tertentu apabila nilai statistik Anderson-Darling pada distribusi tersebut semakin kecil.

4. Dilakukan pendugaan nilai parameter untuk parameter yang terdapan pada ditribusi 3 parameter weibull. Pendugaan parameter dilakukan menggunakan metode Maximum Likelihood dan metode Newton Raphson [5].

5. Pembentukan Model Awal Waktu Survival Menggunakan Regresi Cox.

Sebelum melakukan pemodelan terhadap beberapa faktor yang diduga mempengaruhi waktu survival penderita tuberculosis, terlebih dahulu dilakukan pengujian asumsi pemodelan regresi cox. Apabila asumsi pemodelan regresi cox dari faktor-faktor yang telah diduga terpenuhi, maka faktorfaktor tersebut dapat dimodelkan sesuai distribusi data waktu survival yang diperoleh pada tahap 2c. analisis waktu survival dilakukan dengan metode regresi cox terhadap ketahanan hidup penderita tuberculosis.

6. Uji Kelayakan Model

Pada tahap ini dilakukan uji kelayakan model terhadap model regresi cox yang diperoleh pada tahap sebelumnya.

a. Uji Serentak

Uji serentak ini digunakan untuk mengetahui apakah variabel independen yang digunakan pada model berpengaruh signifikan secara bersama-sama.

Hipotesis:

$\mathrm{H} 0: \beta 1=\beta 2=\cdots=\beta_{p}=0$

$\mathrm{H} 1$ : paling sedikit ada satu $\beta_{j} \neq 0$, dengan $\mathrm{j}=1,2, \cdots, \mathrm{p}$

Taraf Signifikan yang digunakan pada penelitian ini yaitu $5 \%$ atau $\alpha=0,05$

Statistik uji:

$X_{L R}^{2}=-2 \ln \left(\frac{l_{0}}{l_{1}}\right)=2\left(\ln l_{1}-\ln l_{0}\right)=2\left(L_{1}-L_{0}\right)$

Keputusan : tolak HO jika nilai statistik uji $X_{L R}^{2}>\chi_{p ; \alpha}^{2}$

b. Uji Parsial

Uji Parsial untuk mengetahui variabel independen mana yang berpengaruh signifikan terhadap model, maka langkah selanjutnya adalah melakukan uji parsial terhadap parameterparameternya.

Hipotesis:

$\mathrm{HO}: \beta_{j}=0$

$\mathrm{H} 1: \beta_{j} \neq 0$

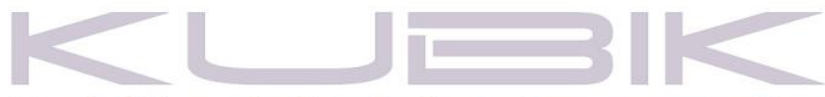

Publikasi Ilmiah Matematika

Taraf Signifikan yang digunakan pada penelitian ini yaitu $5 \%$ atau $\alpha=0,05$

Statistik uji:

$X_{W}^{2}=\left[\frac{\widehat{\beta}_{j}}{\operatorname{SE}\left(\widehat{\beta}_{j}\right)}\right]^{2}$

Keputusan : tolak HO jika nilai statistik uji $X_{W}^{2}>\chi_{l ; \alpha}^{2}$

\section{Hasil dan Diskusi}

Karakteristik penderita TB yang paling banyak dirawat di RSPG Cisarua yaitu dalam rentang usia $42 \mathrm{~s} . \mathrm{d}$ 63 tahun seperti pada Tabel 1.

Tabel 1. Tabel Frekuensi Untuk Variabel Usia

\begin{tabular}{cccc}
\hline Kelas ke- & Usia & Batas Kelas & Frekuensi \\
\hline $\mathbf{1}$ & 9 th -19 th & $8.5-19.5$ & 10 \\
\hline $\mathbf{2}$ & 20 th -30 th & $19.5-30.5$ & 15 \\
\hline $\mathbf{3}$ & 31 th -41 th & $30.5-41.5$ & 11 \\
\hline $\mathbf{4}$ & 42 th -52 th & $41.5-52.5$ & 25 \\
\hline $\mathbf{5}$ & 53 th -63 th & $52.5-63.5$ & 25 \\
\hline $\mathbf{6}$ & 64 th -74 th & $63.5-74.5$ & 10 \\
\hline $\mathbf{7}$ & 75 th -85 th & $74.5-85.5$ & 4 \\
\hline
\end{tabular}




$8 \quad 86$ th -96 th
Total

$85.5-96.5$ 0 100

Gambar 1 menunjukkan bahwa penderita TB sebagian besar berjenis kelamin laki-laki dengan tingkat pendidikan terakhir SD serta memiliki kebiasaan merokok. Berdasarkan informasi yang diperoleh sebagian besar penderita TB berada dilingkungan dengan sanitasi yang baik dan pencahayaan rumah yang bagus.

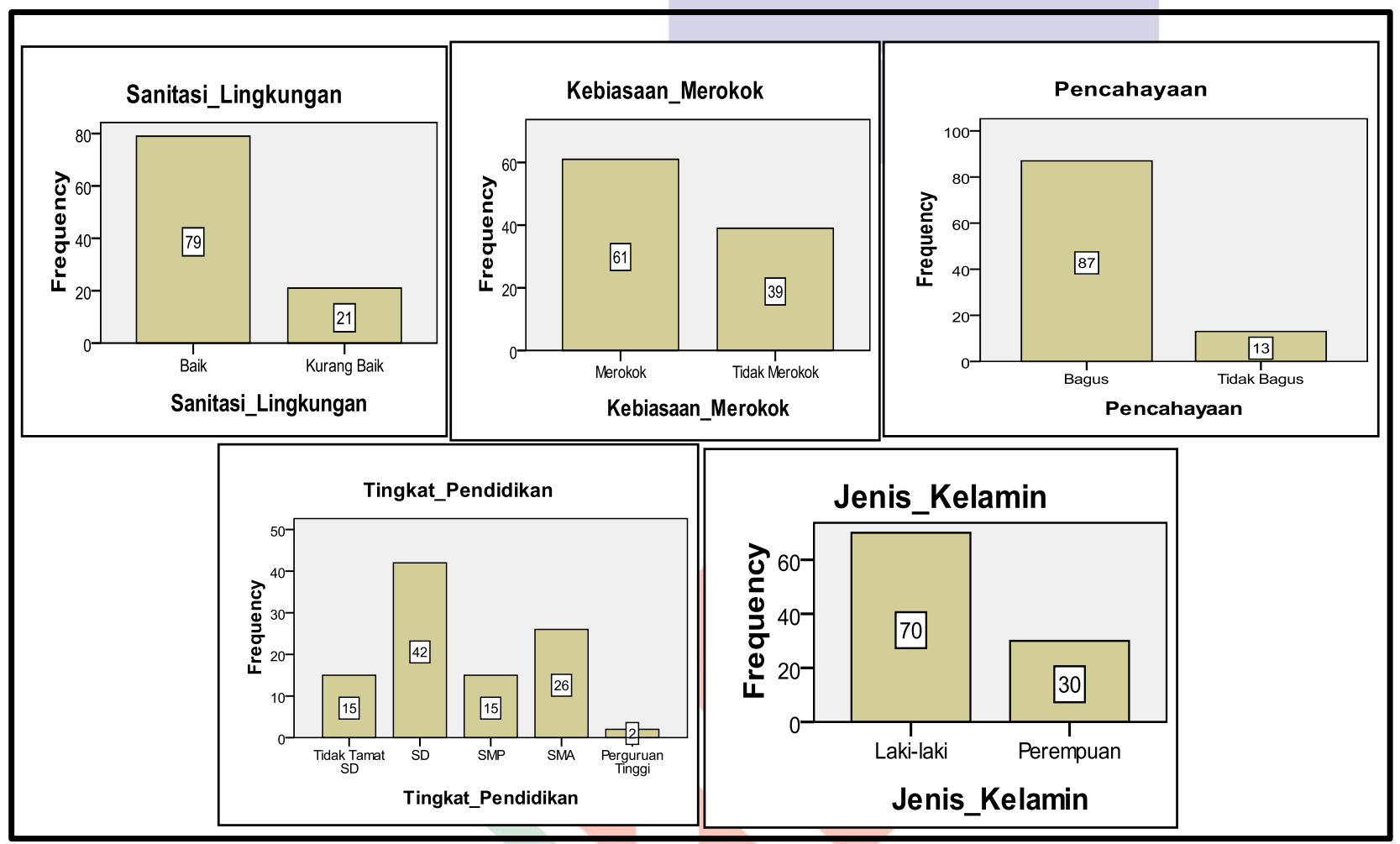

Gambar 1. Bar Chart Penderita TB berdasarkan Variabel Jenis Kelamin, Tingkat Pendidikan Paisen TB Sanitasi lingkungan, kebiasaan merokok dan pencahayaan rumah penderita.

\section{Pendugaan Distribusi Data}

Pendugaan distribusi data dilakykan menggunakan uji Anderson-Darling.Pemilihan distribusi data yang akan digunakan dapat dilihat dari nilai Anderson-Darling yang dihasilkan, nilai yang akan dipilih yaitu nilai yang terkecil dari nilai distribusi yang lainnya dan nilai signifikannya harus lebih besar dari nilai signifikan yang ditentukan yaitu sebesar 0,05

Tabel 2. Pengujian Distribusi Data

\begin{tabular}{lcc}
\hline \multicolumn{1}{c}{ Distribusi } & Anderson-Darling & Signifikan \\
\hline Normal & 5.695 & 0.473 \\
\hline 2-Parameter Exponential & 4.831 & $<0.010$ \\
\hline 3-Parameter Weibull & 1.576 & $>0.500$ \\
\hline Smallest Extreme Value & 10.793 & $<0.010$ \\
\hline Largest Extreme Value & 1.6 & 0.116 \\
\hline Logistic & 3.295 & $>0.250$
\end{tabular}

Tabel 2. Menunjukkan bahwa nilai Anderson-Darling yang paling kecil terdapat pada distribusi 3parameter weibull, selain itu nilai signifikannya lebih besar dari nilai $\alpha$ yaitu $>0.500$. sehingga dapat dikatakan bahwa data waktu survival penderita TB berdistribusi 3-parameter weibull. 


\section{Estimasi Fungsi Hazard dan Fungsi Survival}

Data waktu survival penderita TB yang berdistribusi 3-parameter weibull mempunyai fungsi distribusi sebagai berikut:

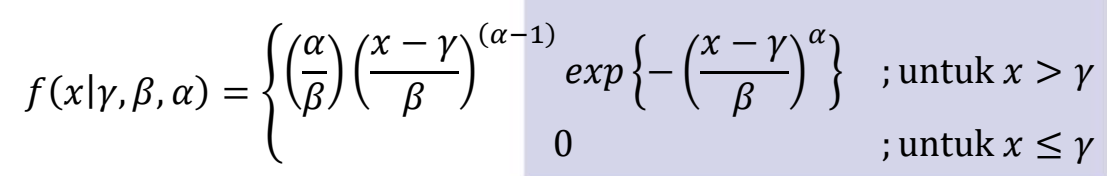

Fungsi kumulatifnya :

$F(t)=\int_{0}^{t} f(x) d x=\int_{0}^{t}\left(\frac{\alpha}{\beta}\right)\left(\frac{x-\gamma}{\beta}\right)^{(\alpha-1)} \exp \left\{-\left(\frac{x-\gamma}{\beta}\right)^{\alpha}\right\} d x=1-\exp \left\{-\left(\frac{t-\gamma}{\beta}\right)^{\alpha}\right\}$

Fungsi Survival :

$S(t)=1-F(t)=1-1-\exp \left\{-\left(\frac{t-\gamma}{\beta}\right)^{\alpha}\right\}=-\exp \left\{-\left(\frac{t-\gamma}{\beta}\right)^{\alpha}\right\}$

Fungsi Hazard :

$h(t)=\frac{f(t)}{S(t)}=\frac{\left(\frac{\alpha}{\beta}\right)\left(\frac{t-\gamma}{\beta}\right)^{(\alpha-1)} \exp \left\{-\left(\frac{t-\gamma}{\beta}\right)^{\alpha}\right\}}{-\exp \left\{-\left(\frac{t-\gamma}{\beta}\right)^{\alpha}\right\}}=-\left(\frac{\alpha}{\beta}\right)\left(\frac{t-\gamma}{\beta}\right)^{(\alpha-1)}$

\section{Estimasi Parameter}

Dalam penelitian ini, fungsi likelihood adalah PDF (Probability Distribution Function) bersama distribusi 3 parameter weibull yang dinyatakan dengan:

$$
\begin{aligned}
L(\gamma, \beta, \alpha)=\prod_{t=1}^{n} f(x \mid \gamma, \beta, \alpha) & =\frac{\alpha}{\beta}\left(\frac{x-\gamma}{\beta}\right)^{\alpha-1} \exp \left\{-\left(\frac{x-\gamma}{\beta}\right)^{\alpha}\right\} \\
& =\left(\frac{\alpha}{\beta^{n}}\right)^{n} \sum_{t=1}^{n}\left(\gamma-x_{i}\right)^{\alpha-1} \exp \left\{-\sum_{t=1}^{n}\left(\frac{x_{i}-\gamma}{\beta}\right)^{\alpha}\right\}
\end{aligned}
$$

Fungsi likelihood merupakan fungsi eksponensial sehingga untuk menyederhanakan fungsi tersebut digunakakan fungsi In-likelihood yaitu

$$
\begin{aligned}
\ln (L(\gamma, \beta, \alpha)) & =n \ln \alpha+\sum_{t=1}^{n} \ln \left(x_{i}-\gamma\right)^{\alpha-1}-n \alpha \ln \beta-\sum_{t=1}^{n}\left(\frac{x_{i}-\gamma}{\beta}\right)^{\alpha} \\
& =n \ln \alpha+(\alpha-1) \sum_{t=1}^{n} \ln \left(x_{i}-\gamma\right)-n \alpha \ln \beta-\sum_{t=1}^{n}\left(\frac{x_{i}-\gamma}{\beta}\right)^{\alpha}
\end{aligned}
$$

\section{Publikasi Ilmiah Matematika}

Fungsi In-likelihood untuk estimasi parameter $\alpha, \beta$, dan $\gamma$ merupakan fungsi maksimum apabila dipenuhi $\frac{\partial \ln (L(\gamma, \beta, \alpha))}{\partial \gamma}=0, \frac{\partial \ln (L(\gamma, \beta, \alpha))}{\partial \beta}=0, \operatorname{dan} \frac{\partial \ln (L(\gamma, \beta, \alpha))}{\partial \alpha}=0$, sehingga

$\frac{\partial \ln (L(\gamma, \beta, \alpha))}{\partial \gamma}=(\alpha-1) \sum_{t=1}^{n} \frac{1}{\left(x_{i}-\gamma\right)}-\frac{\alpha}{\beta} \sum_{t=1}^{n}\left(\frac{x_{i}-\gamma}{\beta}\right)^{\alpha-1}$

$0=(\alpha-1) \sum_{t=1}^{n} \frac{1}{\left(x_{i}-\gamma\right)}-\frac{\alpha}{\beta} \sum_{t-1}^{n}\left(\frac{x_{i}-\gamma}{\beta}\right)^{\alpha-1}$

$\frac{\partial \ln (L(\gamma, \beta, \alpha))}{\partial \beta}=-\frac{n \alpha}{\beta}+\frac{\alpha}{\beta^{\alpha+1}} \sum\left(x_{i}-\gamma\right)^{\alpha}$

$0=-\frac{n \alpha}{\beta}+\frac{\alpha}{\beta^{\alpha+1}} \sum\left(x_{i}-\gamma\right)^{\alpha}$

Sistem persamaan (6) merupakan sistem persamaan nonlinier yang sulit dilakukan penyelesaian eksaknya, sehingga diperlukan penyelesaian dengan pendekatan numerik, salah satunya dengan metode newtonraphson.

Nilai estimasi untuk parameter $\alpha, \beta$, dan $\lambda$ dengan software minitab (Gambar 2) diperoleh shape (parameter bentuk), scale (parameter sakala) dan Threshold (parameter bobot) masing-masing bernilai $1.36794,8.48634$ dan -0.05489 . 


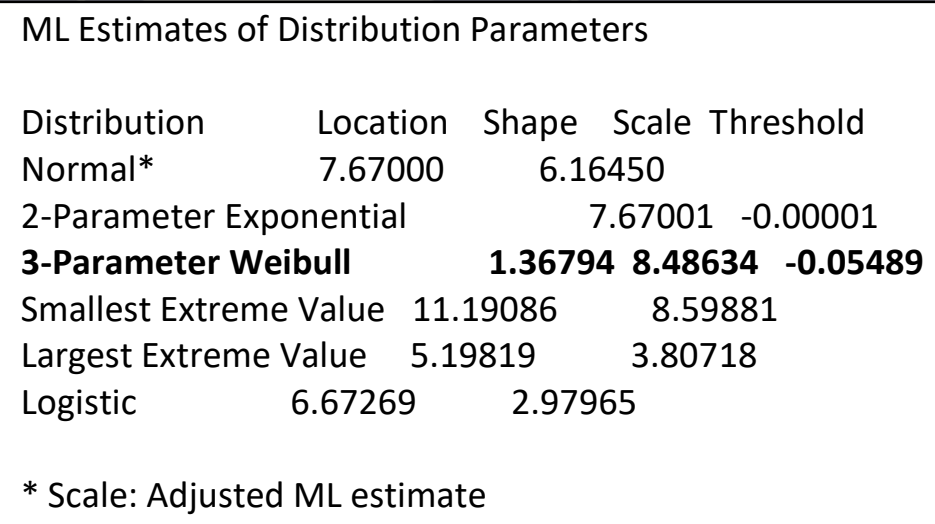

Gambar 2. Nilai parameter yang dihasilkan dengan bantuan Minitab

\section{Pemodelan Waktu Survival Menggunakan Regresi cox}

Nilai parameter model awal Regresi Cox yang dihasilkan dengan bantuan software SPSS seperti pada Tabel 3.

Tabel 3. Nilai Parameter Regresi Cox

\begin{tabular}{|c|c|c|c|c|c|c|c|c|c|}
\hline & & \multirow[t]{2}{*}{ B } & \multirow[t]{2}{*}{ SE } & \multirow[t]{2}{*}{ Wald } & \multirow[t]{2}{*}{ df } & \multirow[t]{2}{*}{ Sig. } & \multirow[t]{2}{*}{$\operatorname{Exp}(B)$} & \multicolumn{2}{|c|}{$95.0 \% \mathrm{Cl}$ for $\operatorname{Exp}(\mathrm{B})$} \\
\hline & & & & & & & & Lower & Upper \\
\hline \multirow[t]{5}{*}{ Step 1} & Usia & -.008 & .019 & .171 & 1 & 679 & .992 & .956 & 1.030 \\
\hline & Jenis_Kelamin & -.195 & .874 & .050 & 1 & .823 & .823 & .149 & 4.560 \\
\hline & Tingkat_Pendidikan & .392 & .296 & 1.755 & 1 & .185 & 1.480 & .829 & 2.643 \\
\hline & Sanitasi_Lingkungan & 1.633 & .662 & 6.082 & 1 & .014 & 5.117 & 1.398 & 18.726 \\
\hline & Kebiasaan_Merokok & .744 & .938 & .629 & 1 & .428 & 2.105 & .335 & 13.240 \\
\hline
\end{tabular}

Model awal Regresi Cox dari penderita ke-i dengan nilai parameter dapat dituliskan sebagai berikut: $h_{i}(t)=\exp \left(-0.008 x_{1}-0.195 x_{2}+0.392 x_{3}+1.633 x_{4}+0.744 x_{5}-0.686 x_{6}\right) h_{0}(t)$

Dilakukan pengujian serentak dan pengujian parsial terhadap model awal regresi cox. Uji serentak ini digunakan untuk mengetahui apakah variabel independen yang digunakan pada model berpengaruh signifikan secara bersama-samablikasi IImiah Matematika Hipotesis:

$H_{0}$ : Variabel yang digunakan tidak berpengaruh secara bersama-sama terhadap model .

$H_{1}$ : Paling sedikit ada satu variabel yang digunakan berpengaruh secara bersama-sama terhadap model.

Nilai -2 Log Likelihood pada setiap langkah untuk pengujian serentak diperoleh seperti pada Tabel 4.

Tabel 4. Nilai -2 Log Likelihood

\begin{tabular}{|l|c|}
\hline Step & $\mathbf{- 2}$ Log Likelihood \\
\hline & 09.346 \\
\hline $\mathbf{1}^{\mathbf{a}}$ & 84.801 \\
\hline $\mathbf{2}^{\mathbf{b}}$ & 84.849 \\
\hline $\mathbf{3}^{\mathbf{c}}$ & 85.038 \\
\hline $\mathbf{4}^{\mathbf{d}}$ & 85.383 \\
\hline $\mathbf{5}^{\mathbf{e}}$ & 86.719 \\
\hline $\mathbf{6}^{\mathbf{f}}$ & 88.550 \\
\hline
\end{tabular}


Taraf signifikan yang digunakan pada penelitian ini yaitu $5 \%$ atau $\alpha=0,05$ dengan Statistik uji: $X_{L R}^{2}=2\left(L_{1}-L_{0}\right)=2(92.346-84.801)=2(7.545)=15.09$

Nilai $L_{1}$ merupakan nilai -2 log likelihood tanpa variabel dan $L_{0}$ merupakan nilai -2 log likelihood dengan variabel. Berdasarkan statistik uji secara serentak terhadap model awal diperoleh nilai sebesar 15,09. Nilai tersebut dibandingkan dengan nilai $\chi_{6 ; \alpha}^{2}$ yaitu 12,591587 , nilai statistik uji menunjukkan lebih besar dibandingkan dengan nilai $\chi_{6 ; \alpha}^{2}$ maka tolak $H_{0}$ artinya ada paling sedikit satu variabel yang berpengaruh terhadap model yang diperoleh. Setelah itu, dilakukan uji parsial terhadap masing-masing variabel.

Taraf signifikan yang digunakan pada penelitian ini yaitu $5 \%$ atau $\alpha=0,05$.

Statistik uji menggunakan persamaan (3) maka diperoleh :

$$
X_{\text {usia }}^{2}=\left[\frac{\hat{\beta}_{\text {usia }}}{S E\left(\hat{\beta}_{\text {usia }}\right)}\right]^{2}=\left[\frac{-0.008}{0.019}\right]^{2}=0.1773
$$

Nilai statistik uji pada variabel usia yaitu 0.1773 dengan nilai $\hat{\beta}$, SE $(\hat{\beta})$ dan nilai Wald untuk variabel lainnya dapat dilihat pada Tabel 5.

Tabel 5. Hasil Uji Parsial Terhadap Model Pertama

\begin{tabular}{lccc}
\hline \multicolumn{1}{c}{ Variabel } & $\widehat{\boldsymbol{\beta}}$ & SE $(\widehat{\boldsymbol{\beta}})$ & Nilai Wald \\
\hline Usia & -0.008 & 0.019 & 0.1773 \\
\hline Jenis Kelamin & -0.195 & 0.874 & 0.0498 \\
\hline Tingkat Pendidikan & 0.392 & 0.296 & 1.7538 \\
\hline Sanitasi Lingkungan & 1.633 & 0.662 & 6.0849 \\
\hline Kebiasaan Merokok & 0.744 & 0.938 & 0.6291 \\
\hline Pencahayaan & -0.686 & 1.115 & 0.3785 \\
\hline
\end{tabular}

Pada Tabel 5 memperlihatkan bahwa nilai statistik uji yang lebih besar ditunjukkan pada variabel sanitasi lingkungan dengan nilai yaitu 6.0849 dan nilai yang paling kecil ditunjukan pada variabel jenis kelamin dengan nilai 0.0498 .

Berdasarkan keputusan dari hasil uji secara serentak maka ada variabel yang tidak berpengaruh secara signifikan terhadap model awal yang dihasilkan. Dilakukan metode backward untuk mengeliminasi variabel yang tidak signifikan terhadap model. Dengan melihat nilai wald yang paling kecil dan dibandingkan dengan nilai $\chi_{1 ; 0.05}^{2}$ yaitu 3.841 , pada Tabel 4 Variabel jenis kelamin yang memiliki nilai wald terkecil diantara variabel lainnya. Nilar wald untuk variabel jenis kelamin Febihkecil dibandingkan dengan nilai $\chi_{1 ; 0.05}^{2}$ artinya variabel jenis kelamin tidak memiliki pengaruh yang signifikan terhadap model dan variabel jenis kelamin tidak digunakan pada model selanjutnya.

Setelah mengeluarkan satu-persatu variabel-variabel yang nilai signifikannya lebih dari 0.05 dengan metode eliminasi backward, maka model terbaik dan estimasi parameter yang diperoleh adalah sebagai berikut:

$$
h_{i}(t)=\exp \left(1.237 x_{4}\right)\left(-\left(\frac{1.36794}{8.48634}\right)\left(\frac{t+0.05489}{8.48634}\right)^{(1.36794-1)}\right)
$$

Nilai estimasi parameter skala, bentuk dan threshold untuk setiap penderitanya sama. Dari hasil model regresi cox tersebut dapat dijelaskan bahwa penderita dengan sanitasi lingkungan kurang baik memiliki resiko tahan hidup dari penyakit TB sebesar $e^{1.237}$ atau sama dengan 3.44 kali dari penderita yang sanitasi lingkungannya kurang baik dan akan meningkatkan fungsi hazard sebesar 3.44. Pada Gambar 3 akan diperlihatkan fungsi hazard untuk setiap penderitanya. 


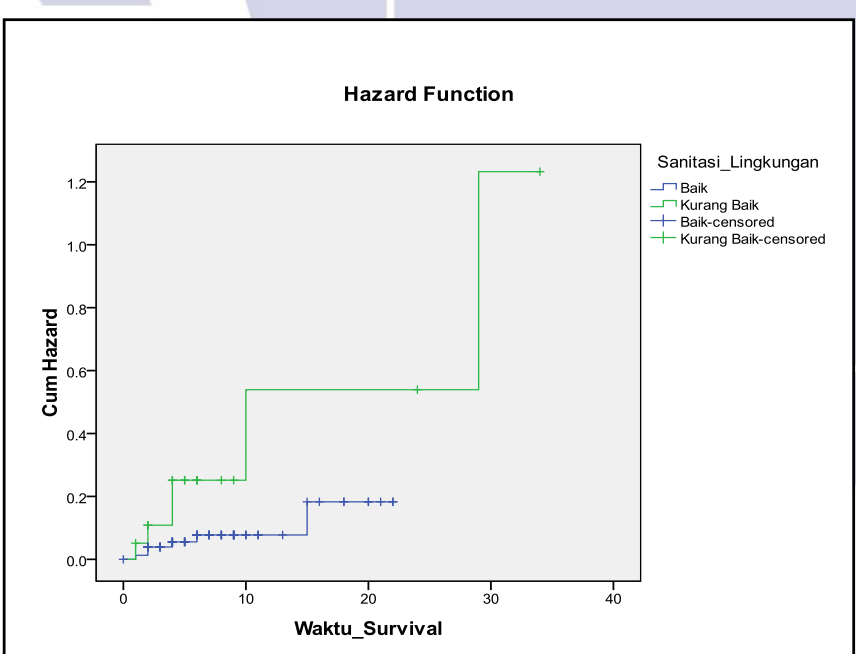

Gambar 3. Grafik Fungsi Hazard Untuk Setiap Penderita Berdasarkan Sanitasi Lingkungannya

Gambar 3 menunjukkan bahwa penderita yang sanitasi lingkungannya kurang baik memiliki fungsi hazard yang lebih tinggi dengan nilai kumulatif hazardnya sebesar 1,232 dibandingkan dengan penderita yang sanitasi lingkungannya baik artinya penderita yang bersanitasi lingkungan kurang baik memiliki resiko gagal untuk bertahan hidup lebih tinggi dibandingkan dengan penderita yang berasnitasi lingkungan baik.

\section{Kesimpulan}

Penderita penderita TB yang menjalani rawat inap di Rumah Sakit Paru Dr. M Goenawan Partowidigdo memiliki karakteristik diantaranya sebagian besar berusia 42-63 tahun, berjenis kelamin laki-laki, pendidikan terakhirnya sebagian besar SD (Sekolah Dasar), pencahayan rumah bagus, sanitasi lingkungannya baik, dan memiliki kebiasaan merokok.

Berdasarkan hasil dari model regresi cox diketahui bahwa sanitasi lingkungan memiliki pengaruh yang paling signifikan terhadap ketahanan hidup penderita TB dengan fungsi hazard yang mengikuti asumsi bahwa data distribusi 3-Parameter Weibull yang diperoleh dari hasil uji Anderson-Darling, dan model regresi cox yang diperoleh dari pembahasan sebelumnya menunjukkan bahwa penderita yang memiliki sanitasi lingkungan yang baik memiliki resiko tahan hidup dari penyakit TB sebesar 3.44 kali dari penderita yang memiliki sanitasi lingkungan yang kurang baik.

\section{Ucapan Terima Kasih Publikasi Ilmiah Matematika}

Ucapan terima kasih penulis sampaikan kepada RSPG Cisarua yang telah memberikan ijin tempat penelitian.

\section{Referensi}

[1] World Health Organization, "Guidelines for prevention of tuberculosis in health care facilities in resource limited settings". Geneva, Switzerland: WHO.1999. http://whqlibdoc.who.int/hq/1999/WHOTB99.269.pdf

[2] Rukmini, Chatarina U.W, "Faktor-Faktor yang Berpengaruh Terhadap Kejadian TB Paru Dewasa di Indonesia (Analisis Data Riset Kesehatan Dasar Tahun 2010)". Buletin Penelitian Sistem Kesehatan. Vol.14 Oktober 2011, p. 320-331.

[3] Liang, C.,Zheng, G., Zhu, N., Zhe, T., Lu, S., dan Chen, L., "A New Environmental Heat Stress Index for Indoor Hot and Humid Envirenments Based on Cox Regression". Journal International of Buliding and Environment, 46, 2472-2479 (2011).

[4] Subekti R, Kusumawati R, "Kajian Partial Least Squares (Studi Kasus: Regresi Cox-PLS)", J. Sains Dasar Vol 3 No.1, 2014, p. 61-86. 
Kubik, Vol. 4 No. 1 Edisi Mei 2019

ISSN : 2338-0896

[5] Ernawatiningsih, Purhadi, "Analisis Survival Dengan Model Regresi Cox: Study Kasus Pasien Demam Berdarah Dengue di Rumah Sakit Haji Surabaya". Jurnal Matematika Vol.2 No.2, Desember 2012, ISSN: 1693-1394

[6] Law, A. M., \& Kelton, D. W., "Simulation Modelling Analysis (3 th ed.)”, New York: MacGraw-Hill, 2000.

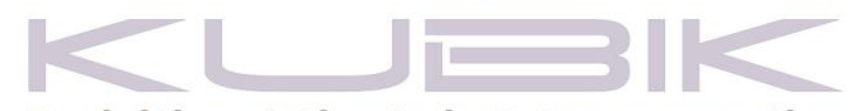

Publikasi IImiah Matematika 